\title{
Influence of pH of the BSA solutions on velocity of the rising bubbles and stability of the thin liquid films and foams
}

\author{
J. Zawala $\cdot$ R. Todorov $\cdot$ A. Olszewska $\cdot$ D. Exerowa • \\ K. Malysa
}

Received: 16 March 2010 / Accepted: 13 May 2010 / Published online: 22 June 2010

(c) The Author(s) 2010. This article is published with open access at Springerlink.com

\begin{abstract}
Influence of $\mathrm{pH}$ of the BSA solutions on velocity of the rising bubbles, stability of foams, and properties of single foam and wetting films was studied. It was found that the solution $\mathrm{pH}$ affected significantly the BSA surface activity and properties of the protein adsorption layer under dynamic and static conditions. At $\mathrm{pH}$ close to the isoelectric point $\left(\mathrm{pH}_{\mathrm{IEP}}=4.8\right)$ the BSA showed the highest surface activity. The equilibrium microscopic foam films of thicknesses of 64-80 nm, depending on the BSA concentration, were obtained at $\mathrm{pH}=5.8$. Under dynamic conditions the bubble rising velocity was reduced in a highest degree and the foam formed were most stable at the solutions $\mathrm{pH}$ 5.8 and 4.8. Lowering the bubble velocity shows that the BSA adsorption layer was formed, which retarded fluidity of the bubble surface. When the solution $\mathrm{pH}$ was significantly lower $(\mathrm{pH}=3.9)$ or much higher $(\mathrm{pH}=10)$ than the $\mathrm{pH}_{\text {IEP }}$ then the BSA practically had no influence on the bubble velocity and the foam stability was drastically reduced. Moreover, the $\mathrm{pH}$ variations affected also the time of the threephase contact (TPC) formation on mica surface covered by the BSA adsorption layers. These $\mathrm{pH}$ dependent changes in the BSA surface activity indicate that the BSA linear conformers, existing at $\mathrm{pH}$ far away from the $\mathrm{pH}_{\mathrm{IEP}}$, have much higher affinity to aqueous phase resulting from higher net electrical charge present over the extended BSA molecule conformers.
\end{abstract}

J. Zawala $(\bowtie) \cdot$ A. Olszewska $\cdot$ K. Malysa

Institute of Catalysis and Surface Chemistry, Polish Academy

of Sciences, 30-239 Cracow, Poland

e-mail: nczawala@cyf-kr.edu.pl

R. Todorov $\cdot$ D. Exerowa

Institute of Physical Chemistry, Bulgarian Academy of Sciences,

Sofia 1113, Bulgaria
Keywords Bovine serum albumin · BSA conformers . Adsorption layer · BSA surface activity $\cdot$ Bubble velocity . Foam film thickness · Foam stability

\section{Introduction}

Protein adsorption at gas-liquid interfaces is important in number of processes and study of the physico-chemical properties of protein adsorption layers continues to be a growing field of research. The early investigations have shown that the protein adsorption layers are formed during a long time, depending on the experimental conditions, the protein nature and surface properties. However, dynamics of the protein adsorption layer (PAL) formation and relationship between interfacial rheology and protein structure remains still unclear (Cascao Pereira et al. 2003a). The bovine serum albumin (BSA) is the protein relatively well characterized because has been used in many studies. The net charge on the protein molecule in the bulk is the $\mathrm{pH}$ dependent and can be either negative or positive, and many properties of protein solutions are determined by the extent of hydrophobic surface exposed at the exterior (Yampolskaya and Platikanov 2006; Patino et al. 2007). In solution the BSA molecule presents a versatile conformation modified by change in $\mathrm{pH}$, ionic strength, presence of ions which influence the protein structure and properties. It is rather generally accepted that near the isoelectric point ( $\mathrm{pH}_{\text {IEP }}$ - ca. 4.7-5.1 (Rezwan et al. 2005; Jachimska et al. 2008) the BSA molecule has a triangular or heart-like shape, while at low $\mathrm{pH}$ (below $\mathrm{pH}=4$ ) the BSA molecule is in an expanded (E) linear state (Cascao Pereira et al. 2003a). The native or normal $(\mathrm{N})$ conformation exists in solution within pH range 4.5-7 (Cascao Pereira et al. 2003a) and this heart-like shape is the most compact structure (Shahid et al. 
1982). Albumin has tree helical homologues domains I, II and III and each domain is made of two subdomains sharing a common helical motif (Khan 1986). The $\mathrm{pH}$ induced conformational transitions are clearly described by Cascao Pereira et al. (2003a). There are presented also schematically the crystal structure of the $\mathrm{N}$ form and configuration of the $\mathrm{F}$ (fast) and $\mathrm{E}$ forms in acidic environment. At $\mathrm{pH}$ from about 4.5 the BSA molecule changes its conformation from $\mathrm{N}$ to $\mathrm{F}$ form, and the $\mathrm{F}$ form is characterized by a longer, less compact and increasingly asymmetric shape of the molecule. The fast $(\mathrm{F})$ form is characterized by increased viscosity, lower solubility and significant loss in helical content (Curvale et al. 2008). At pH below 4 the albumin structure undergoes further expansion into more linear the E form (Cascao Pereira et al. 2003a). This F-E transition causes further losing of the helical content and the molecular hydrodynamic axial ratio is increased (Shahid et al. 1982; Curvale et al. 2008). In alkaline environment the BSA molecule undergoes conformation changes initially into the $\mathrm{B}$ (Basic) form and at $\mathrm{pH}$ ca. 10 into the form A (Aged). There are no proposed structures available but transition to the $\mathrm{B}$ form involves a volume increase and a decrease in helical content (Cascao Pereira et al. 2003a).

The solution $\mathrm{pH}$ affects also surface activity of the BSA. Okubo and Kobayashi (1998) reported that the BSA surface activity was highest within the $\mathrm{pH}$ close to the isoelectric point, and much lower at $\mathrm{pH}=3$ and 11 . For example the surface tension of $0.01 \mathrm{wt} \%$ (ca. $1.5 \times 10^{-6} \mathrm{M}$ ) BSA solution was ca. $52 \pm 1 \mathrm{mN} / \mathrm{m}$ within the region of the isoelectric point and significantly higher (ca. $57 \pm 1 \mathrm{mN} / \mathrm{m}$ ) for both highly acidic $(\mathrm{pH}=3)$ and alkaline $(\mathrm{pH}=11)$ environments. These differences were even larger at lower BSA concentrations (Okubo and Kobayashi 1998). Generally, the bovine serum albumin is highly surface active substance and starts to lower the surface tension at concentrations below $10^{-5}$ wt\% (acetyl BSA) (Graham and Philips 1979a), but the equilibrium layers are formed during a long time (Graham and Philips 1979b; Berthold et al. 2007). Therefore, although all conformers adsorb at the air/water interface, formation of the PAL is strongly $\mathrm{pH}$ dependent.

Bubble rising method is a powerful tool for investigation of adsorption layer formation under dynamic conditions. Velocity of the bubbles rising in surfactant solutions is strongly slowed down (Levich 1962; Clift et al. 1978; Sam et al. 1996; Liao and McLaughlin 2000; Zhang et al. 2001; Zhang and Finch 2001; Krzan and Malysa 2002; Krzan et al. 2004, 2007) due to presence of the adsorption layer at their surfaces. Adsorption layer at the rising bubble surface retards fluidity of the gas/liquid interface and therefore the viscous drag exerted by continuous medium is increased (Levich 1962). When the bubble starts to rise then a non-uniform distribution of surfactant coverage along the bubble surface (dynamic structure of adsorption layer)
(Levich 1962; Dukhin et al. 1995, 1998) starts to be developed, as a result of the viscous drag exerted by continuous medium on the surface. In such adsorption layer, called the dynamic adsorption layer (DAL) (Dukhin et al. 1998), the adsorption coverage (surface concentration) is at minimum at the upstream pole of the moving bubble, while at the rear pole is higher than the equilibrium coverage (Dukhin et al. 1995). This gradient of the surface concentration reduces mobility of the bubble interface, due to surface tension gradients induced, and consequently the bubble velocity is lowered. This causes an increase of the hydrodynamic drag and the bubble velocity can be lowered even by over $50 \%$, at adsorption coverage's assuring complete immobilization of the bubble surface fluidity (Krzan and Malysa 2002; Krzan et al. 2004, 2007; Malysa et al. 2005; Krasowska and Malysa 2007). It was reported by Ybert and di Meglio (1998) that also in BSA solutions of $\mathrm{pH}$ about 5.5 the velocity of the ascending bubbles was strongly reduced compared to the velocity in pure water. They concluded that lowering of the bubble terminal velocity was due to the BSA adsorption that "... progressively modified the hydrodynamic conditions from a stress-free to a rigid sphere ..." i.e. the BSA adsorption layer retarded mobility of the bubble surface. Thus, at the solution $\mathrm{pH}=5.5$ the BSA showed similar effect on velocity of the rising bubbles as typical surfactants.

Under equilibrium conditions the stability of both foam and emulsion films is governed by surface forces between adsorbed protein layers and microscopic foam films are particularly suited for these studies. Investigation of protein foam films formation under varying conditions of $\mathrm{pH}$, ionic strength, and degree of aging at the interface, shows that charged BSA molecules adsorb at the air/water interface in different manner (Cascao Pereira et al. 2003b). The formation of protein adsorption layers with optimal properties, which allow the formation of stable black films, is determined by concentration and the isoelectric point of the protein (Yampolskaya et al. 1977; Yampolskaya and Platikanov 2006). Accordingly, stable films were observed when electrostatic interactions were screened or the proteins were near their isoelectric points. At $\mathrm{pH}<\mathrm{pH}_{\text {IEP }}$ the films either rupture during the process of thinning before the transition to black films or stable thick films are formed. At $\mathrm{pH}>\mathrm{pH}_{\text {IEP }}$ usually thick films become stable, for instance at $\mathrm{pH}=8$ (no salt added) the film thickness of approximately $83 \mathrm{~nm}$ was reported (Clark et al. 1990). These results show the influence of protein solution $\mathrm{pH}$ on the foam film thickness. Aging imparted mechanical rigidity of the interfaces, caused nonuniform film drainage and the prolonged aging resulted in the development of interfacial aggregates (Cascao Pereira et al. 2003b).

The paper presents results of investigation on influence of the solution $\mathrm{pH}$ on the BSA ability to affect velocity of the 
rising bubbles, properties of single foam films and foams formed from the BSA solutions. It was found that the solution $\mathrm{pH}$ affected significantly the velocity of the bubbles rising in BSA solutions and stability of the foams and single foam films.

\section{Experimental}

The measurements of the bubble local velocities and stability of the wetting films formed during bubble collisions with mica surface were carried out using the set-up presented schematically in Fig. 1. Single bubbles were formed at the capillary orifice of inner diameter $0.075 \mathrm{~mm}$ at the bottom of a square glass column and in distilled water the diameter of the bubbles formed was $1.48 \pm 0.01 \mathrm{~mm}$. The bubble motion at various distances from the capillary was monitored and recorded using the Motic Images Plus 2.0 digital recording system. The bubble collision with mica surface and time of rupture of the wetting film formed was recorded using the high speed camera (1182 frames/sec). Sequences of the recorded frames were analyzed frame-by-frame using the image analysis software (SigmaScanPro). Stroboscopic illumination of frequency 100 flashes per second was applied in measurements of the bubble local velocity as a function of distance from the capillary. Details of the set-up and measurement procedures have been described in details elsewhere (Krzan and Malysa 2002; Krzan et al. 2004, 2007; Krasowska and Malysa 2007)

Foam stability measurements were carried out using the set-up consisting of: a) cylinder glass column of inner diameter of $45 \mathrm{~mm}$ with a fritted glass at the bottom, b) syringe pump for supply fixed amount of gas into the solution. Prior the experiments column was carefully filled with $50 \mathrm{ml}$ of the studied solution in such way that no foam was formed. Next, the constant volume of $91 \mathrm{ml}$ of gas was injected through the porous plate forming bubbles. The gas flow rate was strictly controlled and in majority of the experiments the gas velocity was $36 \mathrm{l} / \mathrm{h}$. Heights of the foam and solution columns were started to be measured automatically, immediately after the gas injection, and the profiles of the foam height decay were determined as a function of the time. Details of the set-up and measurement procedures were described in details elsewhere (Lunkenheimer et al. 2008, 2010).

The Scheludko-Exerowa glass cell (Exerowa and Kruglyakov 1998; Platikanov and Exerowa 2005) was used in studies on properties of the single microscopic foam films. The thin liquid film of a constant radius $100 \mu \mathrm{m}$ was formed by withdrawing the liquid from a biconcave drop hanging in the glass film-holding tube of a radius $R=1 \mathrm{~mm}$. The radius ensures the capillary pressure in foam films experiments to be close to those in bubble experiments. This cell is particularly advantageous for determining the ranges of action of long-range and short-range surface forces and the transition between them, as well as the existence of the so-called "metastable" films, i.e. simultaneous co-existence of both thick films and black films (Exerowa and Kruglyakov 1998; Platikanov and Exerowa 2005; Cohen et al. 1992). In order to maintain equilibrium conditions in the cell, concerning temperature $\left(T=22^{\circ} \mathrm{C}\right)$ and vapor pressure, the measurements were performed at least two hours after the tightly closed cell was mounted on the microscope. The thickness of the films was measured using the modernized microinterferometric method of Scheludko and Exerowa (Exerowa and Kruglyakov 1998). In the course of this work the experimental points are determined as the mean values of at least five registered film thicknesses in three separated experiments.

As state of adsorption layers determines also stability of the wetting films so time of the three phase contact (TPC) formation at mica surface by the colliding bubble was studied to determine influence of the BSA solution $\mathrm{pH}$ on stability of the wetting films formed. Two series of the experiments on the three-phase contact (TPC) formation at mica surface modified by BSA adsorption were carried out. In the first series the mica plates were immersed in $1.5 \times 10^{-7} \mathrm{M}$

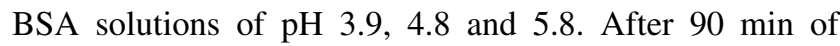
immersion (time available for adsorption $-t_{\mathrm{ads}}$ ), the plates were rinsed with large quantity of distilled water, mounted at distance $L=300 \mathrm{~mm}$ above the capillary orifice and the course of the bubble collision with the plate was recorded in distilled water of $\mathrm{pH}=5.8$. In the second series the mica plates were immersed in $6 \times 10^{-7} \mathrm{M}$ BSA solution of $\mathrm{pH}$ 5.8 for $90 \mathrm{~min}$ and the bubble collision experiments were preformed in water of $\mathrm{pH}=10$.

Materials The bovine serum albumin (BSA) was purchased from Sigma $(M=66.7 \mathrm{kDa})$ and used without further purification. $\mathrm{HCl}, \mathrm{NaOH}$ and $\mathrm{NaCl}$ (Merck) were used for the solution $\mathrm{pH}$ and ionic strength adjustment. To remove eventual organic impurities from $\mathrm{NaCl}$ the reagent sample was heated at $550^{\circ} \mathrm{C}$ for two hours. Four-fold distilled water and freshly cleaved plates of mica were used in the experiments.

\section{Results and discussion}

\subsection{Velocity of the rising bubbles}

The bubble rising velocity is strongly lowered in surfactant solutions due to retardation the bubble surface mobility by the dynamic adsorption layer (DAL) formed (Marangoni effect). Figure 2 presents profiles of the bubble local velocity, i.e. velocity variations with distance from the capillary orifice, in the BSA solutions of $\mathrm{pH}=5.8$. As seen the bubble velocity started to be lowered at extremely low 
Fig. 1 Schematic of the experimental set-up for measurements of the bubble rising velocity and the wetting film stability

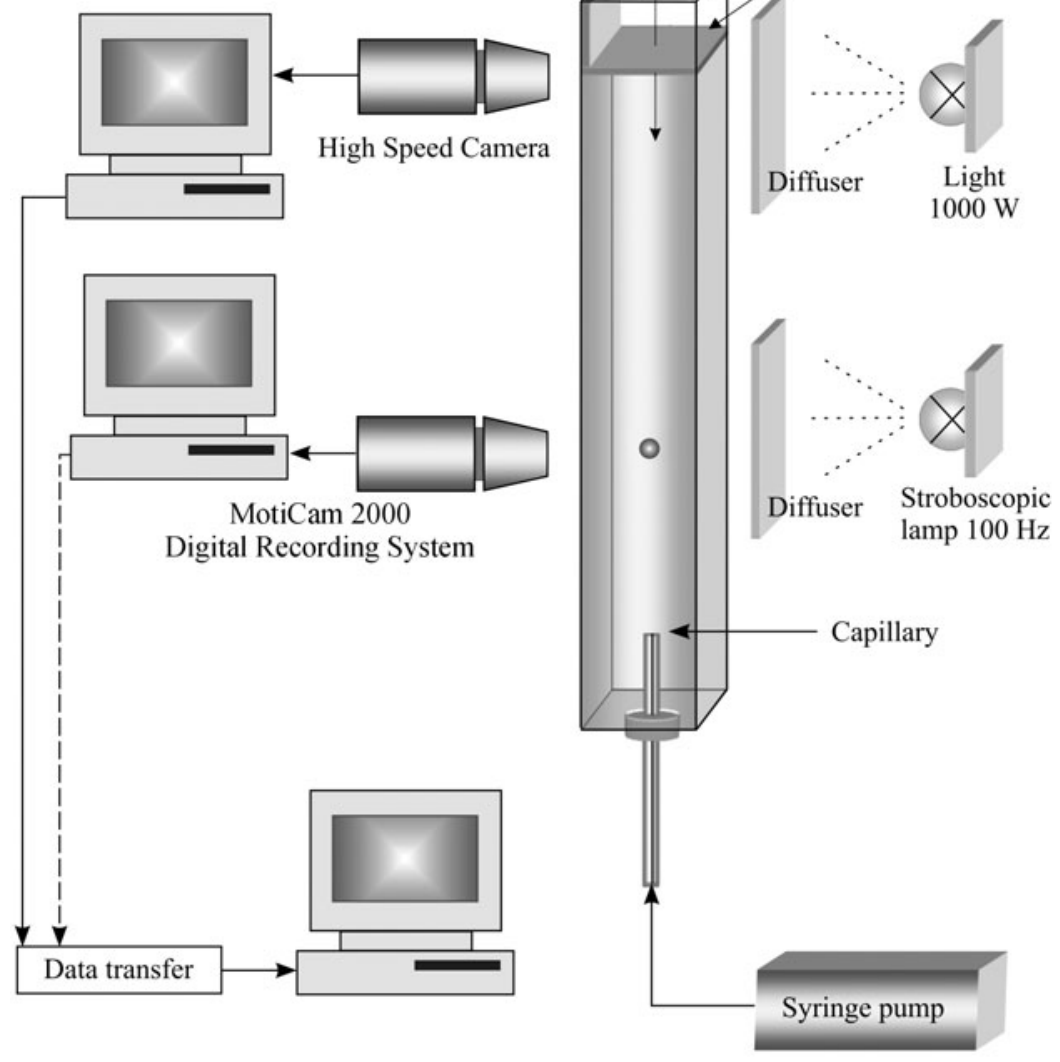

BSA concentrations, $c \geq 4 \times 10^{-8} \mathrm{M}$ of $\mathrm{pH}=5.8$. At lower BSA concentration $\left(c=1.5 \times 10^{-8} \mathrm{M}\right)$ the bubble velocity profile was practically identical as in distilled water, i.e. the detached bubbles accelerated rapidly and then attained (after ca. $40 \mathrm{~mm}$ ) the terminal (constant) velocity of $34.7 \pm 0.3 \mathrm{~cm} / \mathrm{s}$. At the BSA concentrations $c \geq 7.5 \times 10^{-8} \mathrm{M}$ the following three stages of the bubble motion can be observed: i) acceleration, ii) maximum followed by monotonic velocity decrease, and iii) attainment or a tendency to reach the terminal velocity value. With increasing solution concentration the position of the maximum on the local velocity profiles is shifted towards shorter distances, while its height and width are diminishing. Thus, influence of the BSA in solutions of $\mathrm{pH}=5.8$ was similar to that of typical surfactants (Sam et al. 1996; Liao and McLaughlin 2000; Zhang et al. 2001; Zhang and Finch 2001; Krzan and Malysa 2002; Krzan et al. 2004, 2007; Malysa et al. 2005; Krasowska and Malysa 2007). At the highest BSA concentration studied $\left(c=6 \times 10^{-7} \mathrm{M}\right)$ the bubble terminal velocity of ca. $15-16 \mathrm{~cm} / \mathrm{s}$ was attained already at distance of ca. $30 \mathrm{~mm}$ from the capillary orifice and the maximum velocity was only ca. $25 \mathrm{~cm} / \mathrm{s}$.

Figure 3 presents influence of the solution $\mathrm{pH}$ on the local velocity profiles in $6 \times 10^{-7} \mathrm{M}$ BSA solutions. As seen the solution $\mathrm{pH}$ can affect significantly the bubble motion.
Variation of the solution $\mathrm{pH}$ from 5.8 to 4.8 had practically no influence on the bubble velocity profiles. However, when the solution $\mathrm{pH}$ was adjusted to strongly acidic $(\mathrm{pH}=3.9)$ and strongly alkaline $(\mathrm{pH}=10)$ then the bubble motion was almost no affected by the BSA presence. At $\mathrm{pH}=10$ the bubble local velocity profile was identical as for distilled water, while at $\mathrm{pH}=3.9$ the velocity started to be lowered a bit at distances larger than $100 \mathrm{~mm}$ and the velocity lowering was smaller than that one observed at $\mathrm{pH}=5.8$ for BSA concentration of $4 \times 10^{-8} \mathrm{M}$.

The maximum on the bubble local velocity profiles in surfactant solutions indicates, as showed in Krzan et al. (2004, 2007) and Malysa et al. (2005), that the steady-state (uneven) distribution of the surfactant coverage over the bubble surface (dynamic adsorption layer-DAL) has not been established there. Fact that this is also the case in the BSA solutions is proved by the bubble shape variations at different stages of the rising bubbles motion at BSA solution of concentration $6 \times 10^{-7} \mathrm{M}$ and different $\mathrm{pH}$ showed in Figs. 4 and 5. Note please, that besides photos presented in Fig. 4 there are also marked the distances from the capillary orifice and the bubble motion stages, determined from the bubble local velocity profiles (see Fig. 3). As can be observed in Fig. 4 the bubble shape was always spherical at the capillary, but started to be deformed immediately after the 


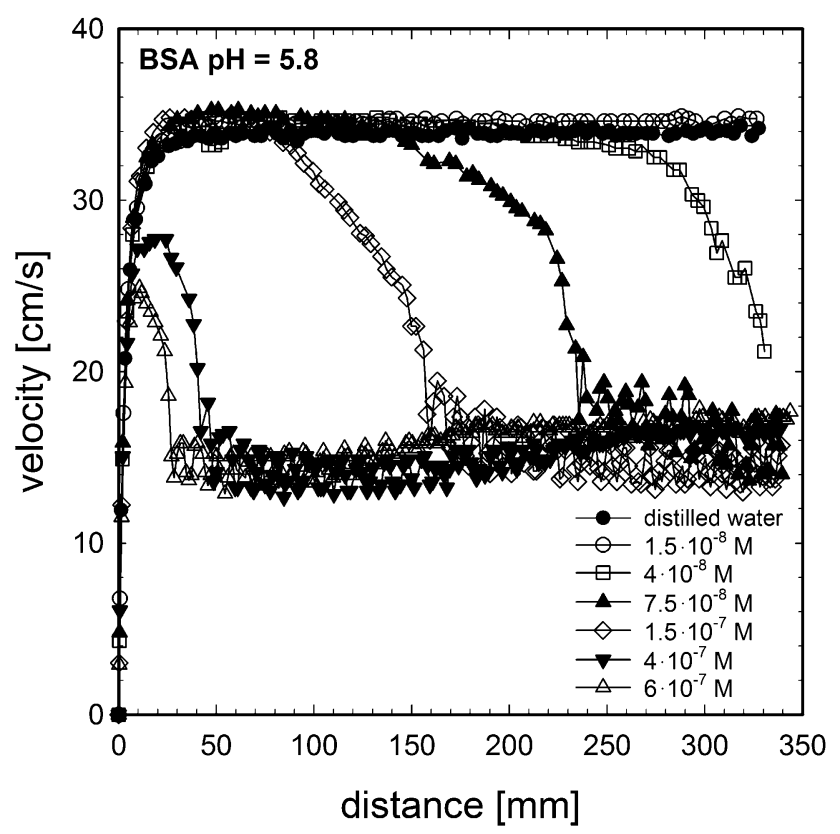

Fig. 2 Profiles of the bubble local velocity in BSA solutions of different concentrations at $\mathrm{pH}=5.8$

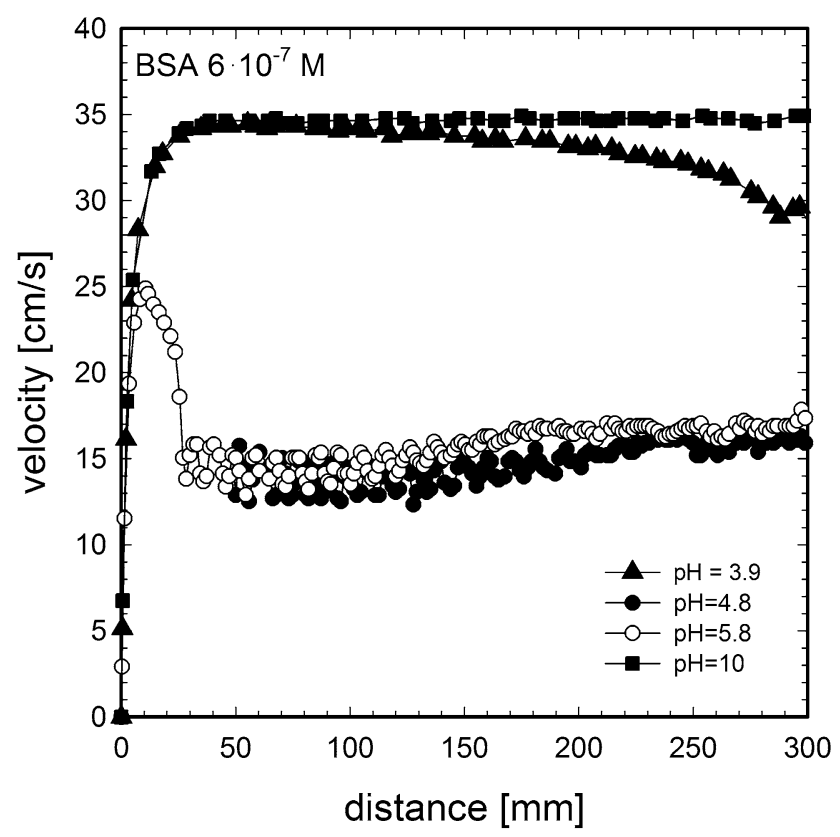

Fig. 3 Influence of the solution $\mathrm{pH}$ on the bubble velocity in $6 \times 10^{-7}$ M BSA solution

detachment. Quantitative data on dependency of the bubble shape deformation, expressed as a ratio of the bubble horizontal and vertical diameters $\left(d_{h} / d_{v}\right)$, with distance from the capillary are presented in Fig. 5 for $6 \times 10^{-7}$ M BSA solution of different $\mathrm{pH}$. As can be noted the bubble shape variations are in a good correlation with the local velocity profiles presented in Fig. 3.
At the solution $\mathrm{pH}$ near the $\mathrm{BSA} \mathrm{pH}_{\mathrm{IEP}}(\mathrm{pH}=4.8$ and 5.8), i.e. when there were three stages of the motion: i) acceleration, ii) maximum followed by monotonic velocity decrease, and iii) attainment of the terminal velocity value, these stages were accompanied by the bubble shape variations (compare Figs. 3-5). At the acceleration stage the bubble shape deformation increases and reaches a maximum value at the point where the bubble velocity was at maximum. Next, the deformation started to decrease (during the deceleration stage) and a constant shape of the bubble was established when the terminal velocity was attained. Shape pulsations mean variations of the interfacial area and adsorption-desorption processes counteracting the surface area variations. It leads to variations in the surface tension gradients induced and fluidity of the bubble interface, which affects strongly the bubble local velocity.

When there was no maximum at the $\mathrm{pH}=10$ and after the acceleration stage the bubble attained its terminal velocity then the bubble had a constant shape obtained at the point of the maximum velocity. Note please that at $\mathrm{pH}=10$ the bubble terminal velocity in $6 \times 10^{-7} \mathrm{M} \mathrm{BSA}$ was the highest, equal to that at distilled water $(34.5 \mathrm{~cm} / \mathrm{s})$, and therefore the bubble shape was distorted in the largest extent. It can be observed in Fig. 6, where influence of $\mathrm{pH}$ on terminal and maximum velocity of the bubbles rising in $6 \times 10^{-7} \mathrm{M}$ BSA solution is presented.

At $\mathrm{pH}=3.9$ the bubble velocity at maximum and the bubble shape deformations were similar as in the solution of $\mathrm{pH}=10$. When at the distance $167 \mathrm{~mm}$ the velocity started to decrease at the solution of $\mathrm{pH}=3.9$ then the bubble shape deformation started also to decrease (see Figs. 3-5). At $\mathrm{pH}=4.8$ and 5.8 the bubble terminal velocity was the lowest (ca. $15 \mathrm{~cm} / \mathrm{s}$ ) and simultaneously the shape deformation were the smallest.

Formation of the dynamic structure of the adsorption layer (DAL) is, as described above, the factor determining local velocity profiles and value of the bubble terminal velocity. When the bubble is formed at the capillary orifice then there is adsorption going on at the growing bubble surface. At the solutions $\mathrm{pH}$ near the $\mathrm{BSA} \mathrm{pH}_{\mathrm{IEP}}$ the bubble velocity started to be lowered at extremely low BSA concentrations, where the diffusion kinetics was very slow. Let's try to estimate degrees of adsorption coverage for two limiting values of the adsorption time: i) time interval between subsequent bubbles detachment $=25 \mathrm{~s}$ and ii) time of the rapid growth of the bubble size (when its radius exceeds the capillary radius $)=1.6 \mathrm{~s}$. The simplified Ward and Tordai solution of the diffusion controlled adsorption model was used as a first approximation (Dukhin et al. 1995):

$\theta_{i}=\frac{2 c}{\Gamma_{\infty}} \sqrt{\frac{D t_{i}}{\pi}} \cdot 100$ 

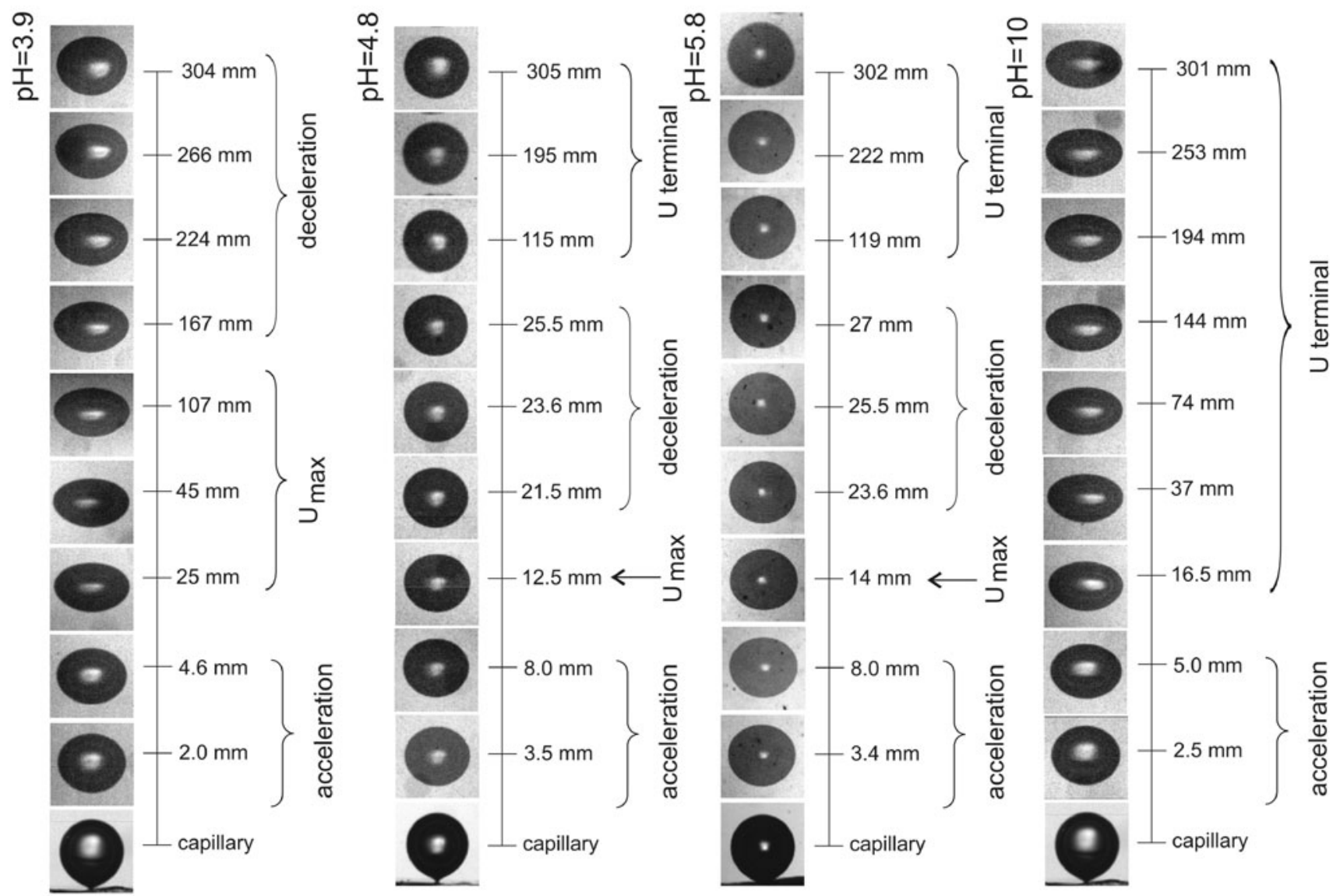

Fig. 4 Bubble rising in solutions of BSA concentration $6 \times 10^{-7} \mathrm{M}$ and different $\mathrm{pH}$

where $\theta_{i}\left(\frac{\Gamma_{i}}{\Gamma_{\infty}}\right)$ is a bubble surface coverage, $c$ is the BSA solution concentration, $t_{i}$ is a adsorption time, $D$ is diffusion coefficient $\left(D=6.7 \times 10^{-11} \mathrm{~m}^{2} / \mathrm{s}\right.$ ) (Ybert and di Meglio 1998) and $\Gamma_{\infty}$ is a surface concentration at close-packed molecules monolayer ranging from 1.5 to $8 \mathrm{mg} / \mathrm{m}^{2}$ (Magdassi and Kamyshny 1996).

Figure 7 presents the bubble surface coverage calculated according to Eq. (1) for $\Gamma_{\infty}=7 \times 10^{-8} \mathrm{~mol} / \mathrm{m}^{2}$ $\left(4.75 \mathrm{mg} / \mathrm{m}^{2}\right.$, that is, an average value of the range $1.5-8$ $\mathrm{mg} / \mathrm{m}^{2}$, the BSA molecular mass $=66.7 \mathrm{kDa}$ ) as a function the BSA concentration, for two different adsorption times $t=1.6 \mathrm{~s}$ and $25 \mathrm{~s}$. Generally, as expected, the adsorption coverage for $t=25 \mathrm{~s}$ is significantly larger than for $t=1.6 \mathrm{~s}$. At the highest BSA concentration the $\theta$ value for $t=25 \mathrm{~s}$ is almost five times larger than for $t=1.6 \mathrm{~s}$. Nevertheless, as can be observed, the bubble surface coverage's calculated are very small (less than $0.05 \%$ ) for both adsorption times, even for the highest BSA concentration studied. This was the reason that there was still a maximum at the bubble velocity profiles (see Fig. 2) even in the case of BSA solution of the highest concentration $\left(6 \times 10^{-7} \mathrm{M}\right)$. The surface coverage present at the bubble interface at the moment of detachment was too small for establishment of the DAL sufficient for immediate immobilization of the interface of the detached bubble. That is why some time (distance) was needed to attained the bubble terminal velocity after its detachment form the capillary orifice.

In acidic and alkaline environments the diffusion kinetics is similar because the BSA concentrations are identical. Thus, lack and/or very small influence of the BSA on the bubble velocity at highly alkaline $(\mathrm{pH}=10)$ and acid $(\mathrm{pH}=3.9)$ indicates that there was no or much smaller BSA adsorption at the bubble surface.

\subsection{Stability of the foams formed}

Foam layer is formed when the number of bubbles arriving (concentrating) at the liquid/gas interface exceeds the numbers of the rupturing ones. Under dynamic conditions the properties and stability of the foam formed depend not only on the composition of the solution but also on the actual (usually non-equilibrium) state of the adsorption layers at both interfaces of the foam films. When the rising bubbles arrive at the solution surface then the foam films start to be formed and the top poles of the bubbles and local areas of the solution surface constitute the bottom and upper 


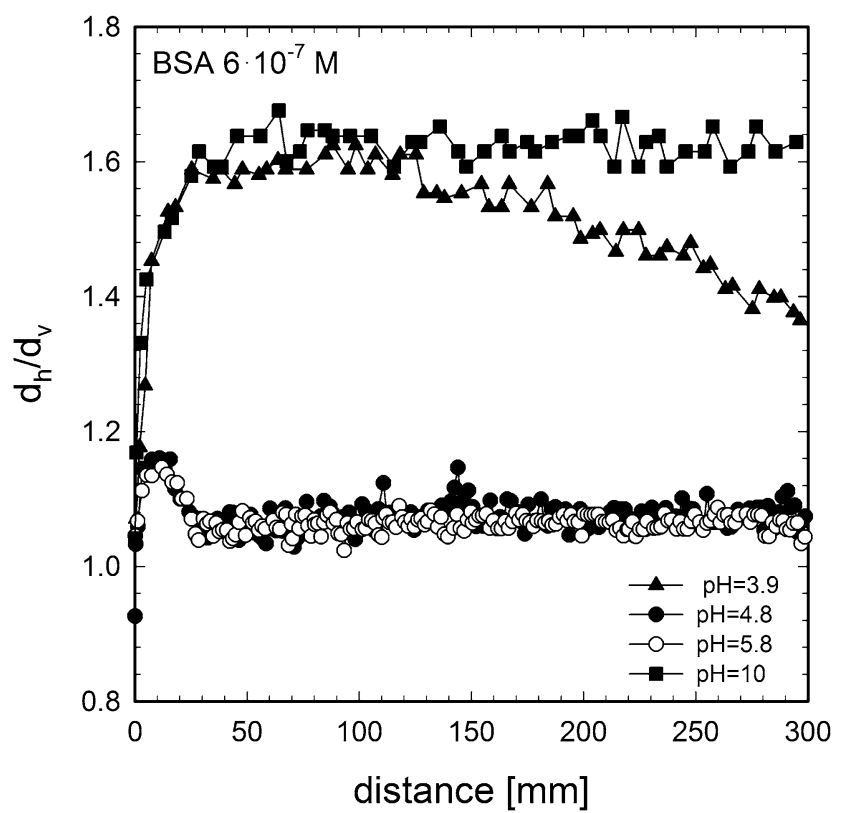

Fig. 5 Variations of the bubble the shape deformation $\left(d_{h} / d_{v}\right)$ with distance from the capillary in $6 \times 10^{-7} \mathrm{M}$ BSA solution

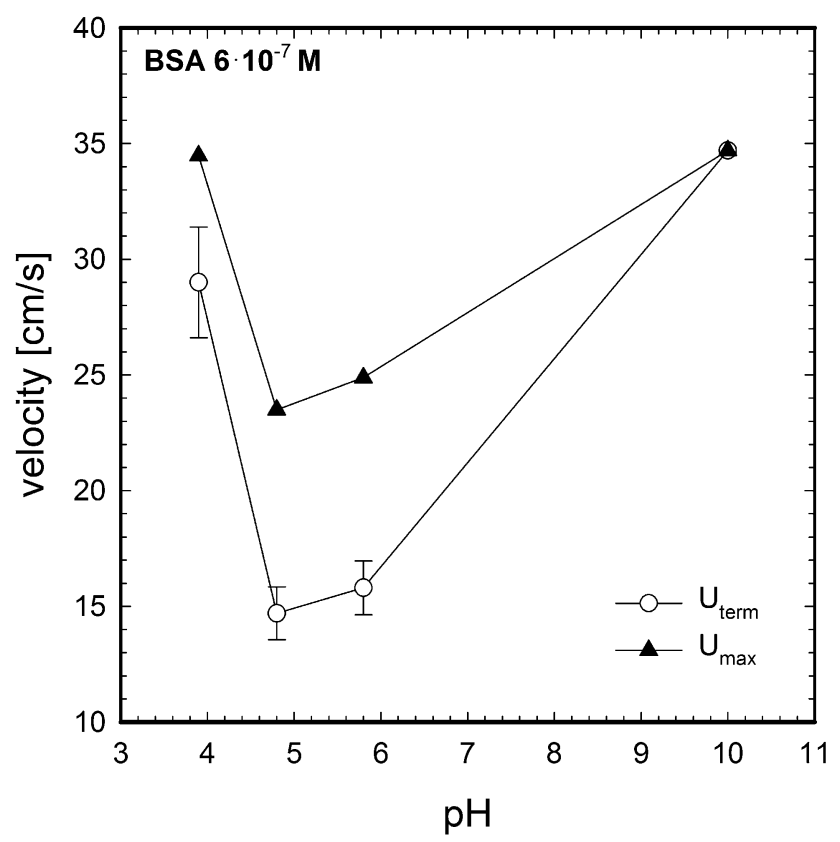

Fig. 6 Influence of $\mathrm{pH}$ on terminal and maximum velocity of the bubbles rising in $6 \times 10^{-7} \mathrm{M}$ BSA solutions

film interfaces. Durability of the foam films formed determines the solution foamability, i.e. "ability" of the system to form foam and the foam stability, i.e. kinetics of the foam column decay (Malysa and Lunkenheimer 2008). It needs to be remembered that during the time of the foam decay the system starts to shift from strictly dynamic conditions towards more and more static, i.e. there is a trend to restore

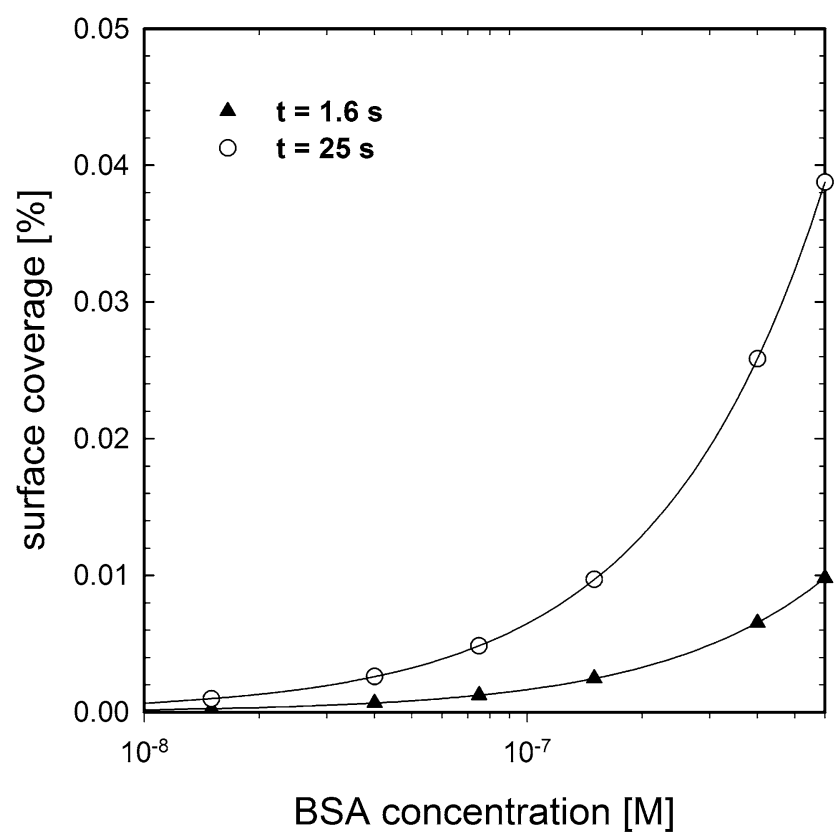

Fig. 7 Surface coverage as a function of the BSA concentration

equilibrium adsorption coverage's and in the case of very stable foam systems the foam films can reach their equilibrium thicknesses.

Figure 8 presents data on influence of the solution $\mathrm{pH}$ on stability of the foams formed from the BSA solutions of concentrations $9 \times 10^{-7}$ and $3 \times 10^{-6} \mathrm{M}$. Generally, it can be noted that the heights of the foam columns formed $(t=0)$ were practically identical for these solution concentrations (see also Fig. 9) at $\mathrm{pH} 5.8$ and 4.8. As seen the decay of the foam columns started immediately after their formation. The decay was quicker in the case of BSA solution of lower concentration $\left(9 \times 10^{-7} \mathrm{M}\right)$. Moreover, variation the solution $\mathrm{pH}$ from 5.8 to 4.8 resulted in increasing the decay velocity, i.e. the foam stability was lowered. At $\mathrm{pH}=3.9$ and 10 , that is far away from the BSA isoelectric point, the stability of the foam was significantly lowered. As can be observed in Fig. 8 there was almost no foam formation-heights of the foam formed were only ca. $15 \mathrm{~mm}$ and the foam ruptured within a few seconds. These dramatic changes can be clearly noted in Fig. 9, where the height of the foam columns at different times after their formation is presented as a function of the $\mathrm{pH}$ for different BSA concentrations. As seen, independently of the BSA concentration, the foam stability was drastically lower at $\mathrm{pH} 3.9$ and 10 , what shows that the BSA adsorption ability was diminished there.

\subsection{Equilibrium microscopic foam films}

Figure 10 shows the effect of BSA concentration on equilibrium thickness $(h)$ of the microscopic foam films. As 

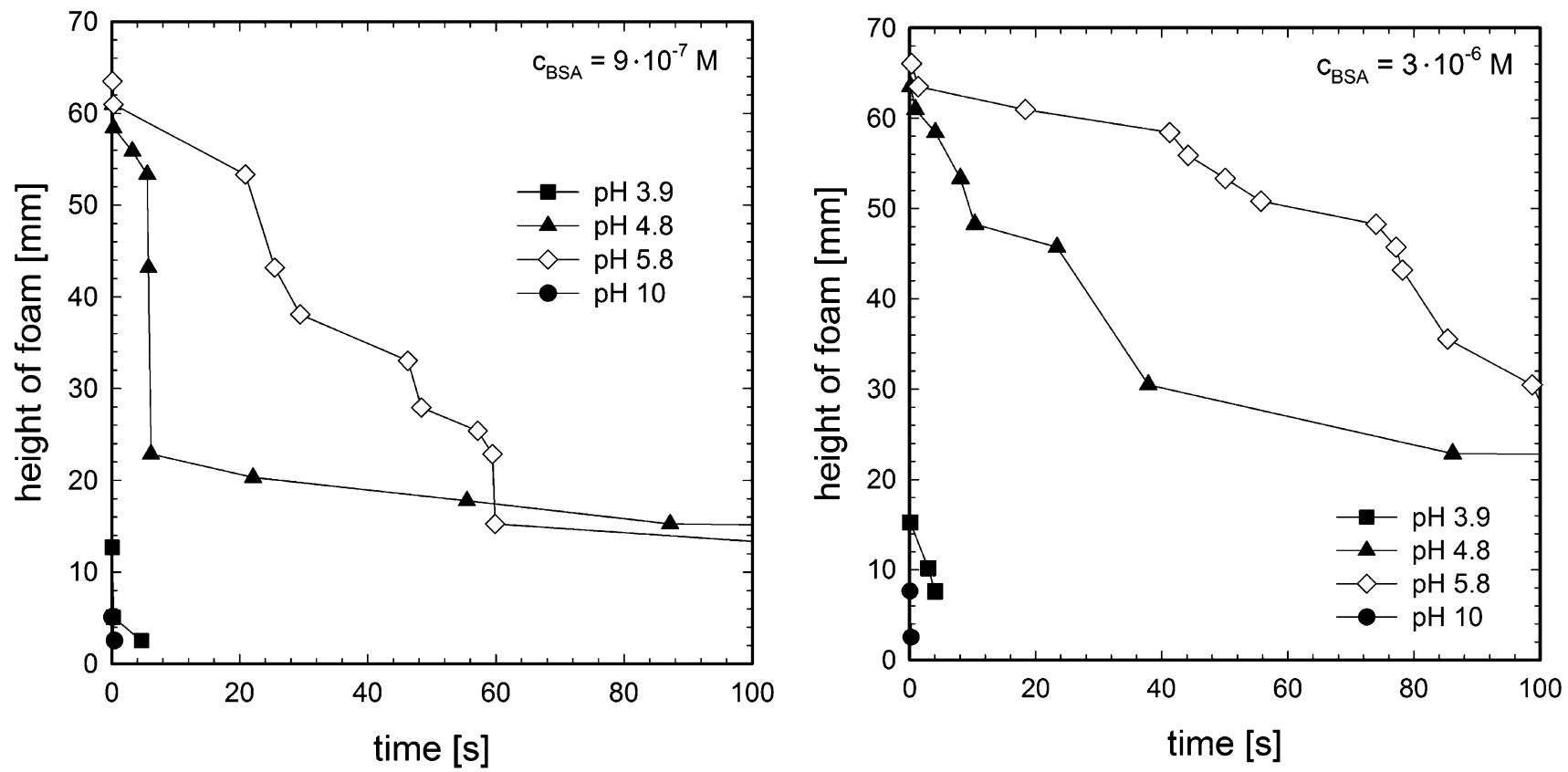

Fig. 8 Influence of solution $\mathrm{pH}$ on stability of the foams formed from BSA solutions of concentrations $9 \times 10^{-7} \mathrm{M}$ and $3 \times 10^{-6} \mathrm{M}$
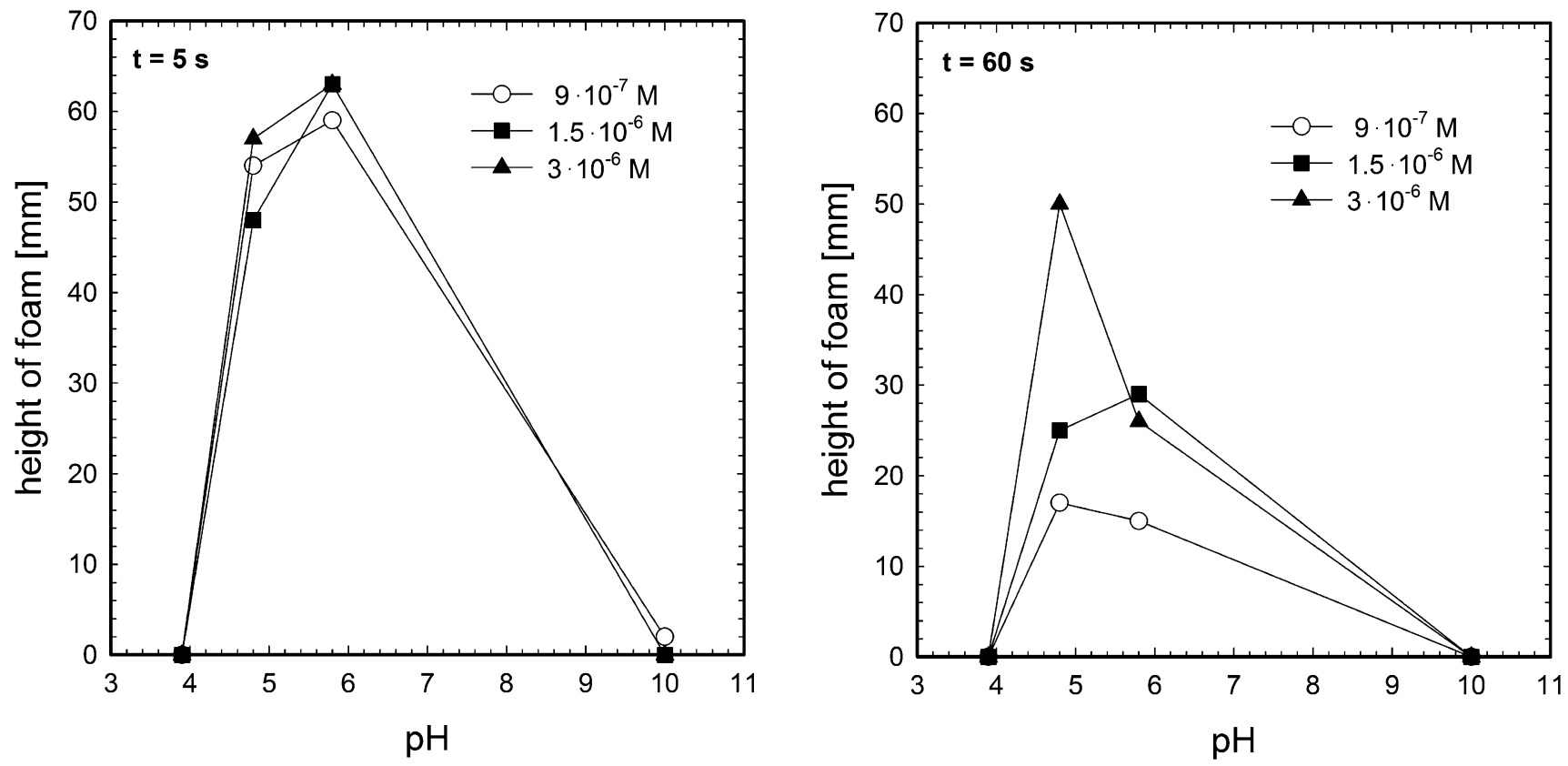

Fig. 9 Height of the foam column, formed from BSA solutions of different concentration, as a function of the solution $\mathrm{pH}$ for the foam lifetimes of 5 and $60 \mathrm{~s}$

seen at the BSA concentration below $5.8 \times 10^{-7} \mathrm{M}$ the thick equilibrium films of thickness $72-79 \mathrm{~nm}$ were obtained, i.e. the films consisting of a thick aqueous core surrounded by the BSA adsorption layers. Within the concentration range of $5.8 \times 10^{-7}-5.8 \times 10^{-6} \mathrm{M}$ BSA the metastable region of the foam films thicknesses was observed. This was the region where both the thick and black films were formed and observed during every experiment. The steady thickness of the black films in the metastable region was equal to $10 \mathrm{~nm}$. Further increase of the BSA concentration resulted in formation of the thick films onlythe film thickness was below $70 \mathrm{~nm}$ due to increasing ionic strength of the BSA solutions (see conductivity data on Fig. 10). 
Fig. 10 Dependences of microscopic foam film thickness $(h)$ and conductivity $(\chi)$ on BSA concentration, $\mathrm{pH} 5.8$

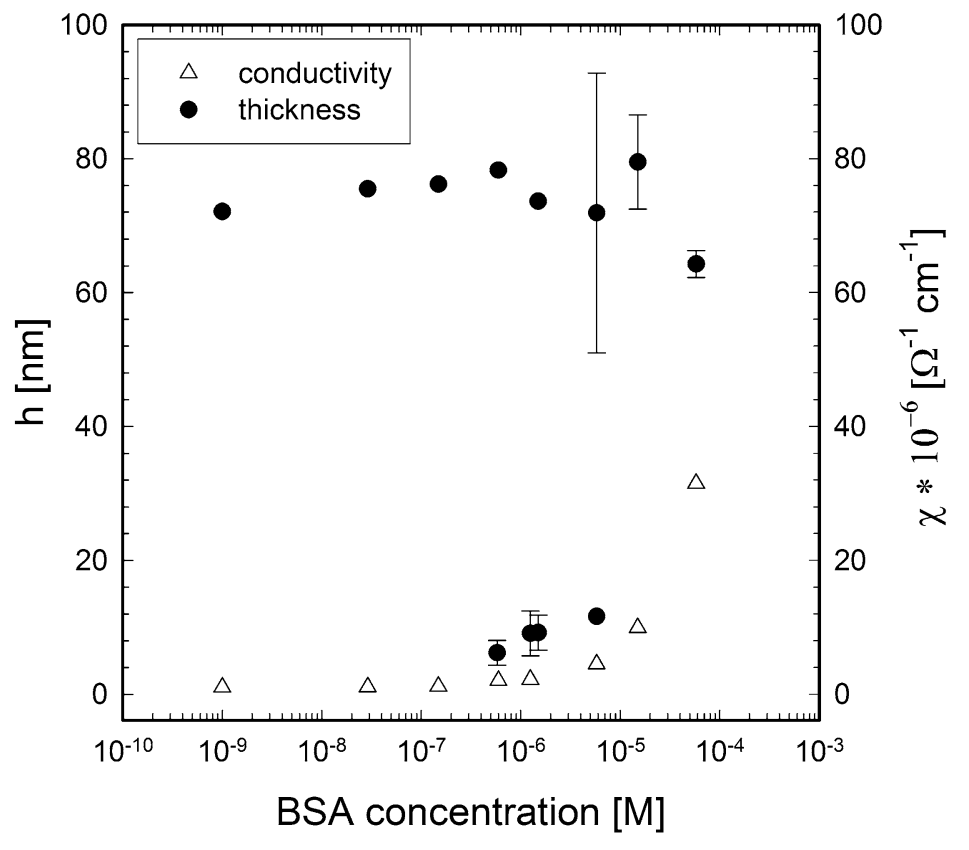

The fluctuations of $h$ in the metastable region can be related to the low barrier in the disjoining pressure isotherm. Such effect has been observed during previous studies of microscopic foam films formed from non-ionic surfactants (Cohen et al. 1992; Todorov et al. 2007). Another explanation of this effect could be that the BSA absolute charge is decreased due to small change in structural conformation and rearrangement of protein molecules at the interface during adsorption. Note please, that the $\mathrm{pH}=5.8$ is close to the $\mathrm{pH}_{\mathrm{IEP}}$. To elucidate the effect of $\mathrm{pH}$ on the foam films formation we investigated the dependence of the film thickness on $\mathrm{pH}$. Dependence of the thickness of the foam films formed from the $1.5 \times 10^{-7} \mathrm{M}$ BSA solution on $\mathrm{pH}$ is shown in Fig. 11. As seen at the region of the isoelectric point $(\mathrm{pH}=4.4$ and 5.2) and at $\mathrm{pH}=10$ the film thickness was zero, that is, it was not possible to obtain the equilibrium films. The films formed were unstable and ruptured due to significantly lower BSA adsorption at $\mathrm{pH}=10$ and diminished electrostatic repulsions at $\mathrm{pH}=4.4$ and 5.2, i.e. at vicinity of the $\mathrm{pH}_{\text {IEP. }}$.

The variation of film thickness with $\mathrm{pH}$ appears to correlate with the change in the extent of electrostatic interaction within the adsorbed BSA layer. At $\mathrm{pH}$ equal or close to the $\mathrm{pH}_{\text {IEP }}$ the films were unstable and ruptured after the appearance of black spots, because the electrostatic repulsion were at a minimum since the net charge within the protein was close to zero. In this case a stable film formation is not possible, because the adsorption layers are not sufficiently densely packed due to very low BSA concentration. At the BSA solutions $\mathrm{pH}$ slightly higher or lower than isoelectric point $(\mathrm{pH}=3.8$ and 5.8) the thick foam films were observed. Therefore, it is clear that the electrostatic repulsion between protein adsorption layers starts to increase as the $\mathrm{pH}$ is shifted from the isoelectric point. At higher $\mathrm{pH}$ $(\mathrm{pH}=10)$ the films were again unstable because an increase in the number of net charges within the protein also reduces its tendency to adsorb at highly alkaline environment (Lu et al. 1999). These results are in a good agreement with data on protein interfacial layers formation on surface of the rising bubbles reported above (see Fig. 3). At $\mathrm{pH}=10$ the bubble terminal velocity was equal to that at distilled water, which indicates that there was no BSA adsorption at the bubble surface. Electrostatic intermolecular repulsions between the cationic or anionic groups in BSA molecules at alkaline $\mathrm{pH}$ are also important factor affecting the BSA adsorption at the interface (Yampolskaya and Platikanov 2006).

Table 1 presents the thickness $h$ of the foam films at the $\mathrm{pH}_{\mathrm{IEP}}$ and $\mathrm{pH} 5.8$ for three different BSA concentrations $\left(c_{\mathrm{BSA}}\right)$. The selected concentrations are outside of the metastable region. At isoelectric $\mathrm{pH}(\mathrm{pH}=4.8)$ for $1.5 \times 10^{-7} \mathrm{M}$ and $1.5 \times 10^{-5} \mathrm{M}$ BSA the ruptured films with black spot formation were observed. Increase of the BSA concentration led to rheological drainage and decreasing in film thickness. The thickness of black foam films is close to those measured at metastable region in Fig. 10. At $\mathrm{pH}$ 5.8 the obtained foam films were the common thick. With the $\mathrm{pH}$ decreasing (from 5.8 to the isoelectric point) the potential of the diffuse electric layer decreases and at $\mathrm{pH} 4.8$ tends to zero. As it was mentioned above, the black foam films are formed when electrostatic repulsion between protein adsorption layers is screened. These results are in conformity with previous reported data for the BSA foam films (Yampolskaya and Platikanov 2006). 


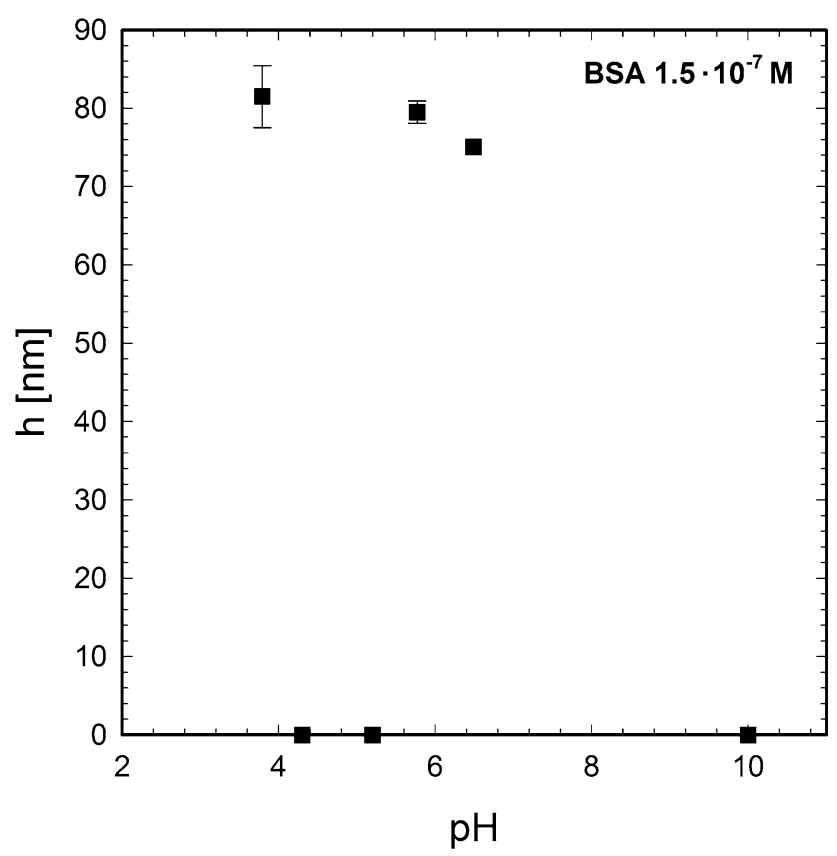

Fig. 11 Influence of solution pH on thickness $(h)$ of equilibrium microscopic foam films formed from BSA solutions of concentrations $1.5 \times 10^{-7} \mathrm{M}$

Table 1 Foam film thickness at different $\mathrm{pH}$ of BSA solution

\begin{tabular}{lll}
\hline$c_{\text {BSA }}[\mathrm{M}]$ & $h[\mathrm{~nm}]$ & \\
\cline { 2 - 3 } & $\mathrm{pH} 4.8$ & $\mathrm{pH} \mathrm{5.8}$ \\
\hline $1.5 \times 10^{-7}$ & ruptured at black spots & 76.2 \\
$1.5 \times 10^{-5}$ & ruptured at black spots & 79.5 \\
$5.8 \times 10^{-5}$ & 20.39 & 64.3 \\
\hline
\end{tabular}

\subsection{Stability of the wetting films at mica with the BSA adsorption layer}

Hydrophobicity of solid surface and electric surface charge of the interacting interfaces are the factors of major importance for stability of the wetting films formed by the colliding bubble and the three phase contact (TPC) formation (Krasowska et al. 2007; Zawala et al. 2008). Mica is a perfectly smooth and hydrophilic solid surface (water contact angle is zero) and there is no TPC formation in distilled water because the wetting film is stable. Thus, monitoring the TPC formation on mica plates with the BSA molecules adsorbed at different solution $\mathrm{pH}$ can supply some information about the BSA molecules conformations. Table 2 presents results of the experiments on the TPC formation in water at mica surface covered by the BSA molecules adsorbed from solutions of different $\mathrm{pH}$. In the first column the details of the mica surface modifications (BSA adsorption conditions) are given, in the second- $\mathrm{pH}$ of the collision experiments, in the third - the times of the TPC formation $\left(t_{\mathrm{TPC}}\right)$, and in the fourth - the photos documenting the experiment outcome. The $t_{\mathrm{TPC}}$ values given in Table 2 are the time intervals from the bubble first collision till the moment of the wetting film rupture and the TPC formation. As can be seen in Table 2 in the case of bubble collision with clean mica plate the wetting film formed at mica surface was stable and the three phase contact was not formed in distilled water. Hydrophilic mica surface is negatively charge in distilled water and shows the zeta potential within the range between -80 and $-120 \mathrm{mV}$ (Scales et al. 1992; Zembala et al. 2003). As the bubble surface is also negatively charged in distilled water with the zeta potential values ranging from $-35 \mathrm{mV}$ (Stockelhuber 2003) to $-65 \mathrm{mV}$ (Graciaa et al. 1995; Lee and Li 2006), so there were repulsive electrostatic interactions between interfaces of the wetting film formed. These repulsive interactions assured stability of the wetting film and prevented the TPC formation.

Adsorption layer of the BSA molecules at the mica surface changed this situation completely-the TPC was always formed. Formation of the TPC on mica with the adsorbed BSA molecules shows that due to the BSA adsorption the wetting film formed was destabilized. As can be seen the $t_{\text {TPC }}$ values were practically identical $(220-230 \mathrm{~ms})$ for the BSA adsorption from the solutions of $\mathrm{pH}=5.8$ and 4.8. The BSA adsorption from the solution of $\mathrm{pH}=3.9$ resulted in shortening the $t_{\mathrm{TPC}}$ value to ca. $110 \mathrm{~ms}$. Additionally, when the bubble collided in water of $\mathrm{pH} 10$ with the mica surface having the BSA adsorption layer formed at $\mathrm{pH}=5.8$, then the TPC was formed only after $30 \mathrm{~min}$. These $\mathrm{pH}$ dependent differences in the $t_{\mathrm{TPC}}$ values indicate that the wetting film destabilization by the BSA molecules adsorbed at the mica surface was due to both increased mica hydrophobicity by the adsorbed BSA molecules and variations of the surface electric charge. Within the $\mathrm{pH}$ near the BSA isoelectric point ( $\mathrm{pH}=4.8$ and 5.8), i.e. when the net electric charge of the adsorbed BSA molecules is small, the effect of the mica surface hydrophobization seems to be the dominating. Fact that the BSA adsorption layer adsorbed at $\mathrm{pH}=3.9$ caused shortening the TPC formation indicates that there were additionally attractive electrostatic interaction between the adsorbed linear the albumin $\mathrm{E}$ form (showing positive net charge) (Cascao Pereira et al. 2003a) and the negatively charged surface of the colliding bubble- these interactions facilitated rupture of the wetting film formed. Prolongation the time of the TPC formation at $\mathrm{pH}=10$ indicates that in these highly alkaline environment there were some additional repulsive electrostatic interaction, i.e. the adsorbed BSA molecules showed some negative electric charge. Appearance of these repulsive electrostatic interactions led to increased stability of the wetting film formed by the colliding bubble and caused this significant prolongation of the $t_{\mathrm{TPC}}$ value.

Let us try to summarize the reasons of differences in the BSA surface activity at different solution $\mathrm{pH}$. According to 
Table 2 Results of the experiments on stability of wetting films formed at the modified mica surfaces by the colliding bubble

\begin{tabular}{|c|c|c|c|}
\hline $\begin{array}{l}\text { System } \\
\text { (1) }\end{array}$ & $\begin{array}{l}\mathrm{pH} \\
(2)\end{array}$ & $\begin{array}{l}t_{\mathrm{TPC}}[\mathrm{ms}] \\
(3)\end{array}$ & $\begin{array}{l}\text { Photo } \\
\text { (4) }\end{array}$ \\
\hline Fresh mica in distilled water & 5.8 & No TPC & \\
\hline $\begin{array}{l}\text { Mica with adsorbed BSA } \\
\left(1.5 \times 10^{-7} \mathrm{M}, \mathrm{pH}=5.8, t_{\mathrm{ads}}=1.5 \mathrm{~h}\right) \\
\text { in distilled water }\end{array}$ & & $220 \pm 110$ & \\
\hline $\begin{array}{l}\text { Mica with adsorbed BSA } \\
\left(1.5 \times 10^{-7} \mathrm{M}, \mathrm{pH}=4.8, t_{\mathrm{ads}}=1.5 \mathrm{~h}\right) \\
\text { in distilled water }\end{array}$ & 5.8 & $230 \pm 60$ & \\
\hline $\begin{array}{l}\text { Mica with adsorbed BSA } \\
\left(1.5 \times 10^{-7} \mathrm{M}, \mathrm{pH}=3.9, t_{\mathrm{ads}}=1.5 \mathrm{~h}\right) \\
\text { in distilled water }\end{array}$ & & $110 \pm 40$ & \\
\hline $\begin{array}{l}\text { Mica with adsorbed BSA } \\
\left(6 \times 10^{-7} \mathrm{M}, \mathrm{pH}=4.8, t_{\mathrm{ads}}=1.5 \mathrm{~h}\right) \\
\text { in distilled water }\end{array}$ & 10 & $\begin{array}{l}\text { TPC formed } \\
\text { after } 30 \mathrm{~min}\end{array}$ & \\
\hline
\end{tabular}

literature data the net charge on the protein is highly $\mathrm{pH}$ dependent, and can contain both negative and positive charge regions. Variations of the protein molecule conformations in the solution bulk, due to the $\mathrm{pH}$ changes, caused the observed significant differences in the BSA surface activity under dynamic and static conditions. At $\mathrm{pH}$ close to the $\mathrm{pH}_{\mathrm{IEP}}$, the BSA showed the highest surface activity, i.e. the bubble rising velocity was significantly reduced as a result of the BSA adsorption at the bubble surface, and stable foam columns were obtained. Moreover, stable microscopic black foam films, which in the case of macromolecules usually can be observed at $\mathrm{pH}_{\text {IEP }}$, were obtained. When the solution $\mathrm{pH}$ was far away (pH 3.9 and 10) from the isoelectric point then the BSA practically did not influenced the bubble velocity (it was practically like in distilled water) and simultaneously, the foamability was drastically reduced. It seems that these variations in the BSA surface activity were caused by an increased affinity of the BSA molecules to the aqueous phase as a result of higher net electrical charge present over the extended BSA molecule conformers. This is also confirmed by the experiments on the TPC formation at mica plate with the BSA adsorption layers obtained at different solution $\mathrm{pH}$. The shortest time of the TPC formation was observed for the BSA adsorption layer obtained at $\mathrm{pH}=3.9$, where the net charge of the BSA molecules was positive. It shows that besides hydrophobization the mica surface there appeared also additional attractive electrostatic interaction at $\mathrm{pH}=3.9$, between the adsorbed BSA molecules showing positive net electric charge and negatively charged surface of the colliding bubble, which facilitated rupture of the wetting film formed.

\section{Conclusions}

The surface activity of the bovine serum albumin (BSA) depends strongly on the solution $\mathrm{pH}$. Highest stability of the foams and largest reduction of the bubble velocity was observed for $\mathrm{pH}=5.8$ and 4.8 of the BSA solutions. When the solution $\mathrm{pH}$ was significantly lower $(\mathrm{pH}=3.9)$ or much higher $(\mathrm{pH}=10)$ then the BSA practically had no influence on the bubble velocity and the foam stability was drastically reduced. As presence of adsorption layer at the liquid/gas interface is necessary for the foam stability and lowering velocity of the rising bubbles so these data clearly illustrate that surface activity of the BSA molecules was much lower at $\mathrm{pH}=3.9$ and 10 , i.e. at the bulk environment where the BSA molecule has increasingly asymmetric (linear) shape.

Variations of the equilibrium foam film thickness with $\mathrm{pH}$ appear to correlate with the change in the extent of the electrostatic interaction within the adsorbed BSA layer. At $\mathrm{pH}=5.8$ the microscopic foam films were the common films of thickness $64-80 \mathrm{~nm}$, depending on the BSA concentration. With the $\mathrm{pH}$ decreasing (from $\mathrm{pH}=5.8$ to 4.8 ) the potential of the diffuse electric layer decreases and at the isoelectric point $(\mathrm{pH}=4.8)$ tends to zero. Therefore, the films were unstable and ruptured after the appearance of black spots, because the electrostatic repulsion were at a minimum since the net charge of the protein adsorption layer was close to zero.

The results obtained indicate that these significant variations in the BSA surface activity at different $\mathrm{pH}$ are due to an increased affinity of the BSA molecules to the aqueous phase, as a result of higher net electrical charge present over the extended BSA molecule conformers. The net charge on the protein molecule in the bulk is the $\mathrm{pH}$ dependent and 
can be either negative or positive. This is also confirmed by the $\mathrm{pH}$ dependent variations of the time of three phase contact formation $\left(t_{\mathrm{TPC}}\right)$ at mica plate with the BSA adsorption layers, which hydrophobized the mica surface. Shortening the $t_{\mathrm{TPC}}$ at $\mathrm{pH}=3.9$, in comparison to $\mathrm{pH} 4.8$ and 5.8 , indicates the existence of additional attractive electrostatic interaction between the adsorbed positively charged linear albumin $\mathrm{E}$ form and the negatively charged surface of the colliding bubble. Much longer $t_{\mathrm{TPC}}$ at $\mathrm{pH}=10$ indicates that there were additional repulsive electrostatic interaction between the negatively charged bubble surface and similarly charged BSA molecules present at the mica surface.

Acknowledgements Scientific cooperation within Polish-Bulgarian Joint Research Project and financial support from Ministry of Science and Higher Education (grants Nos. 1206/GDR/2007/03 and 45/NCOST/2007/0) are acknowledged with gratitude.

Open Access This article is distributed under the terms of the Creative Commons Attribution Noncommercial License which permits any noncommercial use, distribution, and reproduction in any medium, provided the original author(s) and source are credited.

\section{References}

Berthold, A., Schuber, H., Brandes, N., Kroh, L., Miller, R.: Behaviour of BSA and of BSA-derivatives at the air/water interface. Colloids Surf. A 301, 16-22 (2007)

Cascao Pereira, L.G., Johansson, Ch., Radke, C.J., Blanch, H.W.: Surface forces and drainage kinetics of protein-stabilized aqueous films. Langmuir 19, 7503-7513 (2003b)

Cascao Pereira, L.G., Theodoly, O., Blanch, H.W., Radke, C.J.: Dilatational rheology of BSA conformers at the air/water interface. Langmuir 19, 2349-2356 (2003a)

Clark, D.C., Coke, M., Mackie, A.R., Pinder, A.C., Wilson, D.R.: Molecular diffusion and thickness measurements of proteinstabilized thin liquid films. J. Colloid Interface Sci. 138, 207-219 (1990)

Clift, R., Grace, J.R., Weber, N.E.: Bubbles, Drops and Particles. Academic Press, New York (1978), Chap. 9

Cohen, R., Exerowa, D., Kolarov, T., Yamanaka, T., Muller, V.: Thickness transitions in lysolecithin foam films. Colloids Surf. A $\mathbf{6 5}$, 201-209 (1992)

Curvale, R., Masuelli, M., Padilla, A.P.: Intrinsic viscosity of bovine serum albumin conformers. Int. J. Biol. Macromol. 42, 133-137 (2008)

Dukhin, S.S., Kretzschmar, G., Miller, R.: Dynamics of Adsorption at Liquid Interfaces. Theory, Experiments, Application. Elsevier, Amsterdam (1995)

Dukhin, S.S., Miller, R., Loglio, G.: Physico-chemical hydrodynamics of rising bubble. In: Möbius, D., Miller, R. (eds.) Drops and Bubbles in Interfacial Research, pp. 367-433. Elsevier, New York (1998)

Exerowa, D., Kruglyakov, P.: In: Mobius, D., Miller, R. (eds.) Foam, and Foam films Elsevier, Amsterdam (1998)

Graciaa, A., Morel, G., Saulner, P., Lachaise, J., Schechter, R.S.: The $\zeta$-potential of gas bubbles. J. Colloid Interface Sci. 172, 131-136 (1995)

Graham, D.E., Philips, M.C.: Proteins at liquid interfaces: I. Kinetics of adsorption and surface denaturation. J. Colloid Interface Sci. 70(3), 403-414 (1979a)
Graham, D.E., Philips, M.C.: Proteins at liquid interfaces: II. Adsorption isotherms. J. Colloid Interface Sci. 70(3), 415-426 (1979b)

Jachimska, B., Wasilewska, M., Adamczyk, Z.: Characterization of globular protein solutions by dynamic light scattering, electrophoretic mobility and viscosity measurements. Langmuir $\mathbf{2 4}$, 6866-6872 (2008)

Khan, M.Y.: Direct evidence for the involvement of domain III in the $\mathrm{N}-\mathrm{F}$ transition of bovine serum albumin. Biochem. J. 236, $307-$ 310 (1986)

Krasowska, M., Kolasinska, M., Warszynski, P., Malysa, K.: Influence of polyelectrolyte layers deposited on mica surface on wetting film stability and bubble attachment. J. Phys. Chem. C 111, 57435749 (2007)

Krasowska, M., Malysa, K.: Kinetics of bubble collision and attachment to hydrophobic solids: I. Effect of surface roughness. Int. J. Miner. Process. 81, 205-216 (2007)

Krzan, M., Lunkenheimer, K., Malysa, K.: On the influence of the surfactant's polar group on the local and terminal velocities of bubbles. Colloids Surf. A 50, 431-441 (2004)

Krzan, M., Malysa, K.: Profiles of local velocities of bubbles in nbutanol, n-hexanol and n-nonanol solutions. Colloids Surf. A 207, 279-291 (2002)

Krzan, M., Zawala, J., Malysa, K.: Development of steady state adsorption distribution over interface of a bubble rising in solutions of n-alkanols (C5, C8) and n-alkyltrimethylammonium bromides (C8, C12, C16). Colloids Surf. A 298, 42-51 (2007)

Lee, J.S.H., Li, D.: Electroosmotic flow at a liquid-air interface. Microfluid. Nanofluid. 2, 361-365 (2006)

Levich, V.G.: Physicochemical Hydrodymanics. Englewood Cliffs, Prentice-Hall (1962)

Liao, Y., McLaughlin, J.B.: Bubble motion in aqueous surfactant solutions. J. Colloid Interface Sci. 224, 297-310 (2000)

Lu, J.R., Su, T.J., Thomas, R.K.: Structural conformation of bovine serum albumin layers at the air-water interface studied by neutron reflection. J. Colloid Interface Sci. 213, 426-437 (1999)

Lunkenheimer, K., Malysa, K., Wienskol, G., Baranska, M.: European patent bulletin, 16.01.2008 (Art. 97(3) EPC), European Patent No. 1416261 (03024 885.0)

Lunkenheimer, K., Malysa, K., Winsel, K., Geggel, K., Siegel, St.: Novel method and parameters for testing and characterization of foam stability. Langmuir 26(6), 3883-3888 (2010)

Magdassi, S., Kamyshny, A.: Introduction-surface activity and functional properties of proteins. In: Magdassi, S. (ed.) Surface Activity of Proteins-Chemical and Physicochemical Modifications, pp. 1-38. Marcel Dekker, New York (1996)

Malysa, K., Krakowska, M., Krzan, M.: Influence of surface active substances on bubble motion and collision with various interfaces. Adv. Colloid Interface Sci. 114-115, 205-225 (2005)

Malysa, K., Lunkenheimer, K.: Foams under dynamic conditions. Curr. Opin. Colloid Interface Sci. 13, 150-162 (2008)

Okubo, T., Kobayashi, K.: Surface tension of biological polyelectrolyte solutions. J. Colloid Interface Sci. 205, 433-442 (1998)

Patino, J.M.R., Nino, M.R.R., Sánchez, C.C.: Physico-chemical properties of surfactant and protein films. Curr. Opin. Colloid Interface Sci. 12, 187-195 (2007)

Platikanov, D., Exerowa, D.: Thin films. In: Lyklema, H. (ed.) Fundamentals of Interface and Colloid Science, vol. V. Academic Press, San Diego (2005)

Rezwan, K., Meier, L.P., Gauckler, L.J.: A prediction method for the isoelectric point of binary protein mixtures of bovine serum albumin and lysozyme adsorbed on colloidal titania and alumina particles. Langmuir 21, 3493-3497 (2005)

Sam, A., Gomez, C.O., Finch, J.A.: Axial velocity profiles of single bubbles in water/frother solutions. Int. J. Miner. Process. 47, 177196 (1996) 
Scales, P.J., Grieser, F., Healy, T.W., White, L.R., Chan, D.Y.C.: Electrokinetics of the silica-solution interface: a flat plate streaming potential study. Langmuir 8, 965-974 (1992)

Shahid, F., Gomez, J.E., Brinbaum, E.R., Darnall, D.W.: The lanthanide-induced N-F transition and acid expansion of serum. Albumin. J. Biol. Chem. 257, 5618-5622 (1982)

Stockelhuber, K.W.: Stability and rupture of aqueous wetting films. Eur. Phys. J. E 12, 431-435 (2003)

Todorov, R., Cohen, R., Exerowa, D.: Foam films from dipalmitoyl phosphatidylcholine (DPPC) and its natural mixtures. Colloids Surf. A 310, 32-38 (2007)

Yampolskaya, G., Platikanov, D.: Proteins at fluid interfaces: adsorption layers and thin liquid films. Adv. Colloid Interface Sci. 128130, 159-183 (2006)

Yampolskaya, G.P., Rangelova, N.I., Bonrova, L.E., Platikanov, D.N., Izmailova, V.N.: The formation of foam black films of proteins. Biophysica 22, 939-945 (1977)
Ybert, C., di Meglio, J.-M.: Ascending air bubbles in protein solutions. Eur. Phys. J. B 4, 313-319 (1998)

Zawala, J., Drzymala, J., Malysa, K.: An investigation into the mechanism of the three-phase contact formation at fluorite surface by colliding bubble. Int. J. Miner. Process. 88, 72-79 (2008)

Zembala, M., Adamczyk, Z., Warszynski, P.: Streaming potential of mica covered by latex particles. Colloids Surf. A 222, 329-339 (2003)

Zhang, Y., Finch, J.A.: A note on single bubble motion in surfactant solutions. J. Fluid Mech. 429, 63-66 (2001)

Zhang, Y., McLaughlin, J.B., Finch, J.A.: Bubble velocity profile and model of surfactant mass transfer to bubble surface. Chem. Eng. Sci. 56, 6605-6616 (2001) 